\title{
GIS-BASED SURFACE ANALYSIS OF ARCHAEOLOGICAL FINDS
}

\author{
K. Kovács, K. Hanke, M. Moser \\ Institute of Basic Sciences in Civil Engineering, Surveying and Geoinformation Unit, University of Innsbruck, Austria \\ (kristof.kovacs, klaus.hanke, michael.t.moser)@uibk.ac.at
}

KEY WORDS: Reconstruction, Surface Analysis, Tool Marks, GIS, Laser Scanning

\begin{abstract}
:
The international research project HiMAT (History of Mining Activities in the Tyrol and adjacent areas) is dedicated to the study of mining history in the Eastern Alps by various scientific disciplines. The aim of this program is the analysis of the mining activities' impacts on environment and human societies. Unfortunately, there is only a limited number of specific regions (e.g. Mitterberg) to offer possibilities to investigate the former mining expansions. Within this multidisciplinary project, the archaeological sites and finds are analyzed by the Surveying and Geoinformation Unit at the University of Innsbruck. This paper shows data fusion of different surveying and post-processing methods to achieve a photo-realistic digital 3D model of one of these most important finds, the Bronze Age sluice box from the Mitterberg. The applied workflow consists of four steps: 1. Point cloud processing, 2. Meshing of the point clouds and editing of the models, 3. Image orientation, bundle and image adjustment, 4. Model texturing. In addition, a short range laser scanning survey was organized before the conservation process of this wooden find. More accurate research opportunities were offered after this detailed documentation of the sluice box, for example the reconstruction of the broken parts and the surface analysis of this archaeological object were implemented using these high-resolution datasets. In conclusion, various unperceived patterns of the wooden boards were visualized by the GIS-based tool marks investigation.
\end{abstract}

\section{KURZFASSUNG:}

Das internationale Forschungsprojekt HiMAT (Die Geschichte des Bergbaus in Tirol und seinen angrenzenden Gebieten) beschäftigt sich mit der Forschung der Bergbaugeschichte in den Ostalpen in Kooperation verschiedener wissenschaftlicher Disziplinen. Das Ziel dieses Programms ist die Analyse der Auswirkungen des Bergbaus auf die Umwelt und die Gesellschaft. Leider, es gibt nur einige spezifische Regionen, wie zum Beispiel den Mitterberg, wo man die ehemaligen Bergbauaktivitäten untersuchen kann. Innerhalb dieses multidisziplinären Projekts analysiert der Arbeitsbereich Vermessung und Geoinformation an der Universität Innsbruck die archäologischen Grabungen und Funde aus den Schlüsselgebieten. Dieser Artikel präsentiert das Zusammenspiel verschiedener Vermessungstechniken und Post-Processing Methoden, um ein fotorealistisches, digitales 3D Modell dieses wichtigen bronzezeitlichen Holzkastens vom Mitterberg zu erstellen. Der Arbeitsablauf besteht aus vier Schritten: 1. Verarbeitung der Punktwolken, 2. Vermaschung dieser Punktwolken und Bearbeitung der Modelle, 3. Bild Orientierung, Bündelausgleichung und Farbkorrektur, 4. Texturierung der Modelle. Eine detaillierte Dokumentation wurde mit einem Nahbereichs-Laserscanner erzielt. Weitergehende Forschungsmöglichkeiten konnten aufgrund dieser Detail-Dokumentation des Holzkastens angeboten werden. Zum Beispiel wurden die Rekonstruktion der gebrochenen Teile und eine Oberflächen-Analyse dieses archäologischen Objekts mit diesen hochauflösenden Datensätzen machbar. Abschließend wurden verschiedene unbemerkte Bearbeitungsspuren der Holzbretter durch die GIS-basierte Analyse sichtbar gemacht.

\section{INTRODUCTION}

\subsection{Archaeological documentation with 3D laser scanners in HiMAT special research program}

The archaeological documentation with laser scanner systems provides various object analysis opportunities during data processing. The photorealistic virtual reconstruction of finds constitutes a huge potential of digital investigation, and the newly acquired knowledge helps to understand the issues of archaeological researches (Hanke et al. 2010).

The advancement of the laser scanning systems is the non destructive way of high-quality geometric data collection in a short period of time (Petrie et al. 2009), which offers exact documentation opportunity in the archaeological science as well. Since 2007, the Surveying and Geoinformation Unit at the University of Innsbruck has regularly applied terrestrial- and short range laser scanners for archaeological documentation within the HiMAT (History of Mining Activities in the Tyrol and adjacent areas) program. Different post-processing methods could also have been improved during the last years.

For example, data acquisition was organized with a Trimble GX 3D laser scanner in the cave of "Mauken E" near Brixlegg, Austria in 2008 and 2009 (Figure 1). After the georeferencing, the terrestrial laser scanning model was combined with the digital terrain model, which provided the precise spatial position of the cave. This information was especially relevant in the archaeological work because the gangs of the cave were compared with the digital terrain model and further potential entrances could be prospected by these results. In addition, accurate volume calculations were accomplished in digital environment between the excavation layers, which helped to appreciate the copper quantity between these layers.

The documentation of "Mauken F" excavation, near Brixlegg, Austria was another important research project (Figure 1). The data collection at the site was accomplished with a terrestrial laser scanner in the fall of 2007 and in the summer of 2008. The nine excavation situations were scanned during seven days from overall 44 various positions. The point resolution was between 
3 and 5 millimetres. The archaeological site was also recorded with a Nikon D200 calibrated digital camera during the terrestrial laser scanning (TLS) surveys and the relationship between the object (model) space and the image (photos) space was determined in workflow bundle adjustment. As a result, it was possible to arrange the texturing with visibility analysis and the photo-realistic three-dimensional digital model of "Mauken F" excavation was created after the fusion of TLS- and closerange photogrammetry datasets (Kovács et al. 2009).

The finds of "Mauken F" excavation were digitized with a Faro short range laser scanner system in 2007 as well. The most important archaeological object was the approximately $80 \mathrm{~cm}$ long, 3000 years old wooden washing trough. After the digital modelling, the high-resolution three-dimensional datasets of these finds offered further research opportunities (Moser et al. 2009).

One of the most significant finds was the Bronze Age sluice box from Mitterberg, Austria, which was documented with a combination of different surveying methods in 2009 and 2010. After the short range laser scanner data collection and digital model creation, the reconstruction of the broken parts and the surface analysis of this archaeological object were also feasible. This paper demonstrates the developed documentation workflow of the sluice box and in addition, the results of different spatial analysis techniques are discussed as well.

\subsection{Description of the archaeological site and find}

The excavations were accomplished in an industrial area alongside the famous main load mining area at the Mitterberg, Austria during the last years (Figure 1). This mine can be considered as one of the largest Bronze Age mining districts in Europe. Aside the mining depressions, an extensive area of orebeneficiation is known (Stöllner 2008). A region of wet beneficiation and an ore-washery were discovered in 2008 and 2009 by the help of previous archaeological studies. The approximately $1.5 \mathrm{~m} \times 1.5 \mathrm{~m}$ wide and $0.5 \mathrm{~m}$ high fully preserved sluice box was found in the centre of these installations and in this object ore was washed and perhaps heavier, fine grinded ore residua were concentrated as well in the early times.

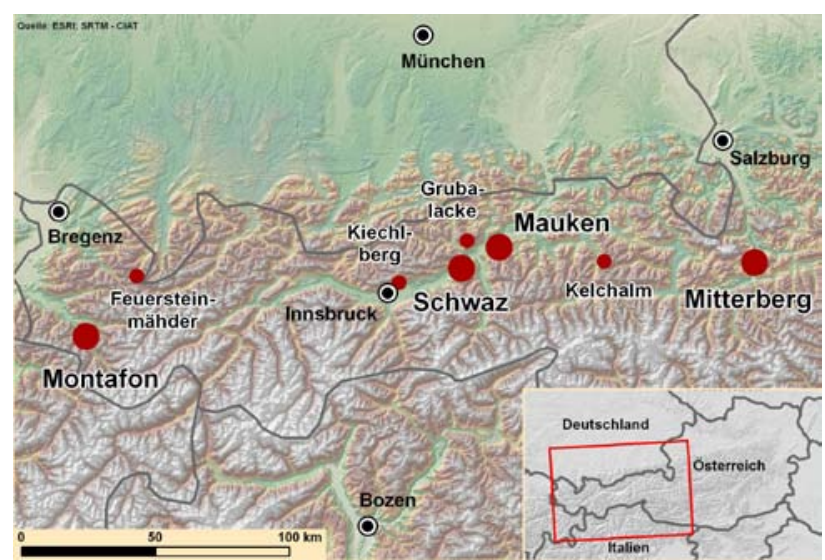

Figure 1. The key areas of HIMAT special research project, such as Mitterberg and Mauken

It was possible to investigate the Bronze Age mounting techniques of the wooden boards and the related tool marks because the wooden construction and the surfaces of the find were undamaged.

\section{ARCHEOLOGICAL DOCUMENTATION OF THE SLUICE BOX}

\subsection{Data acquisition at the archaeological site and photo- realistic digital model creation}

At the archaeological site, the in-situ data acquisition was accomplished with the Trimble GX 3D terrestrial laser scanner and a Nikon D200 calibrated digital camera in the fall of 2009 (Figure 2). The resolution for the two excavation layers was 2 $\mathrm{mm}$, and the surrounding area was scanned with the resolution of $20 \mathrm{~mm}$. The two epochs were documented from a total of 14 different scanning positions and the volume of the raw dataset was in the order of 14 million points. The eighty photos provided accurate image data for texturing the digital model of the archaeological site.

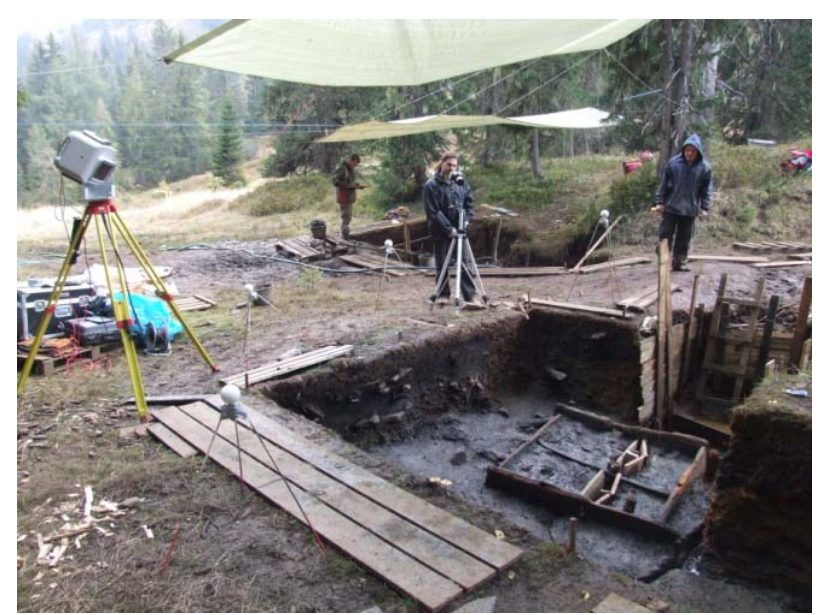

Figure 2. Data collection at the archaeological site with different survey methods

The methodology of the photo-realistic digital model creation can be summarized in the following way. The point cloud processing was the first step of the workflow since the raw data was captured from every scanning position in the local coordinate system during the TLS survey. Therefore, the different point clouds were registered and georeferenced into a common coordinate system by spherical targets.

The second step implied the meshing of these point clouds and the editing of the digital models in InnovMetric PolyWorks ${ }^{\circledR}$ Software. This part of the workflow included the data triangulation and some model processing techniques, for instance filling small holes. The created digital 3D models of the two excavation layers consisted of 5.5 million triangles. To keep the data volume manageable this number could be heavily reduced by $90 \%$ without significant geometric loss in the digital model. The third step was image orientation, bundle adjustment and image colour correction (Figure 3). This step performed within PhotoModeler ${ }^{\circledR}$ resulted in a consistent and oriented bundle of images providing homogeneous texture to the entire 3D model of the two excavation layers (Figure 4). 


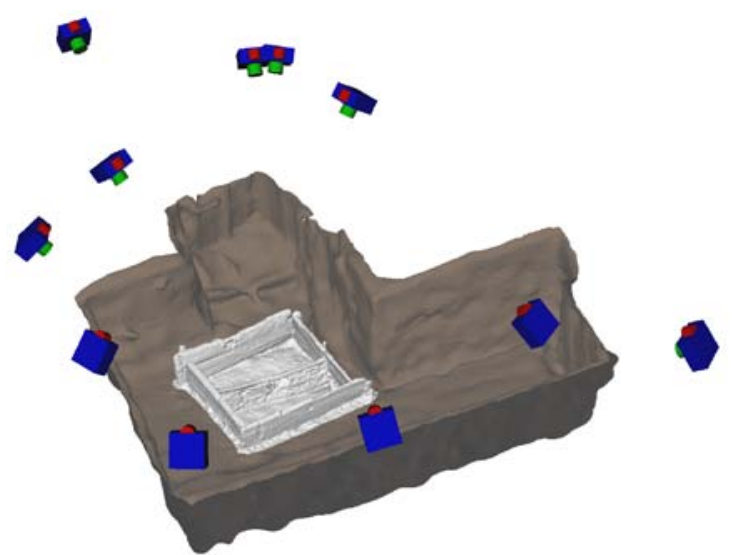

Figure 3. Positions of the digital cameras after bundle adjustment

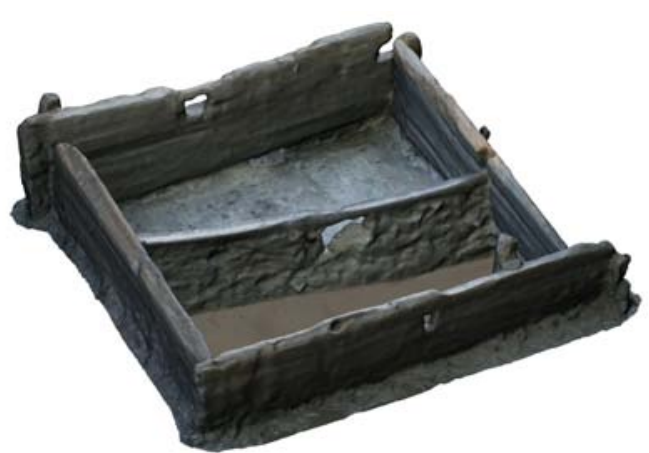

Figure 4. The photo-realistic three-dimensional digital model of the sluice box

To get a more detailed documentation of these important finds and to have an accurate digital 3D model of the damageable and sensible wooden parts for further archaeological analyses an additional short range laser scanning was accomplished

\subsection{Short range laser scanning survey for a high-resolution digital model}

Before the conservation process of this sluice box started, the Surveying and Geoinformation Unit of the University of Innsbruck initiated a close range laser scanning with a FARO ScanArm in early 2010 (Figure 5). The aim of this work was an all-round data collection for a high detailed digital model. The selected resolution of this data acquisition was $0.2 \mathrm{~mm}$. The overall thirty-one wooden objects and object parts were documented during three days and the volume of the raw dataset was in the order of 440 million points.

The point cloud registration was implemented without artificial targets in this post processing workflow. The different sides of the wooden objects were adjusted in a common reference system by "Best Fit Alignment" method and after the data registration the maximum residual between the overlapping areas was less than $1 \mathrm{~mm}$.

The point clouds then were triangulated and processed mainly with automatic techniques in InnovMetric PolyWorks ${ }^{\circledR}$. However, the filling of the small holes had to be carried out manually, because the data collection was unfeasible on some complex surface areas, for example at several "micro wood cracks".

Finally, the all-side documentation of the sluice box was successfully achieved and as a result, the high-resolution three- dimensional digital models of the wooden objects were created. The overall virtual reconstruction of this unique find from 31 digital models signified the following research challenge discussed in the next chapter.

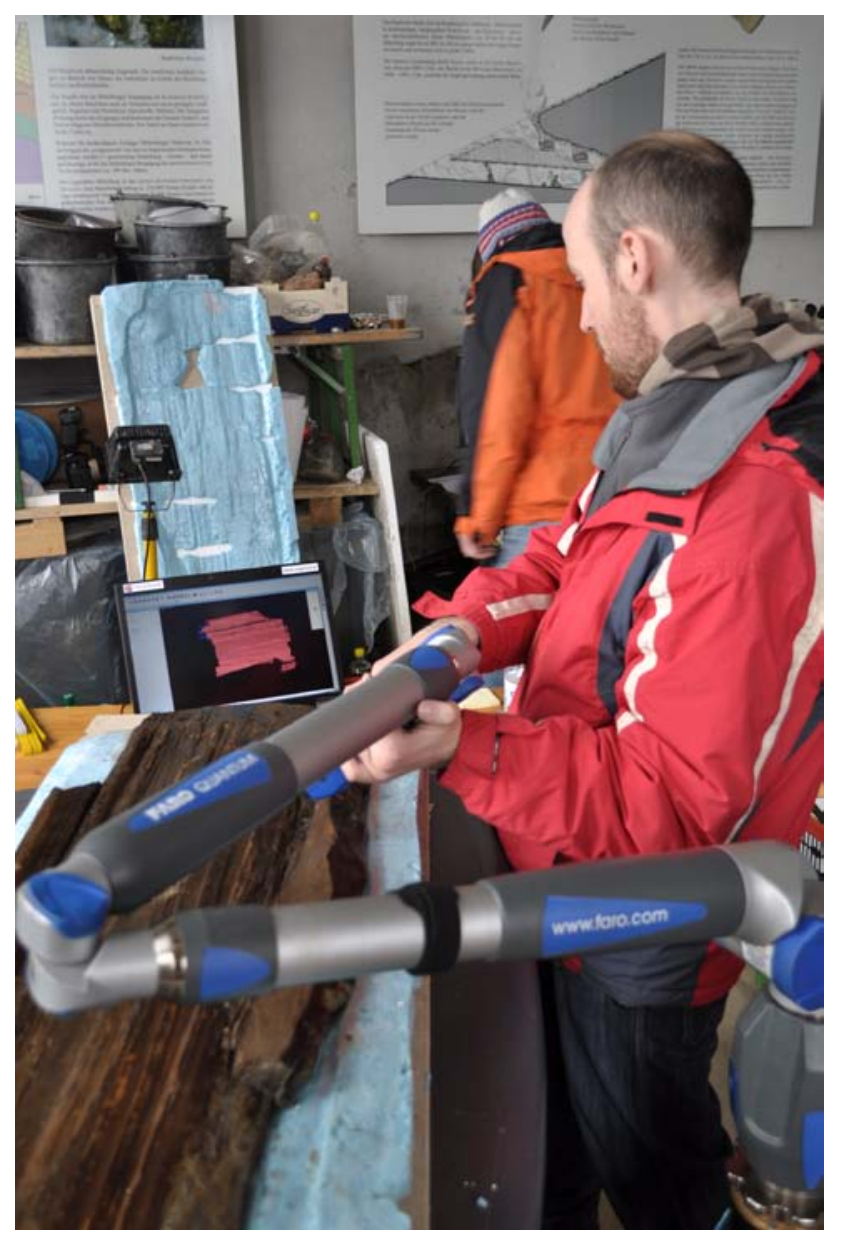

Figure 5. The documentation of the sluice box with the FARO ${ }^{\circledR}$ close range laser scanner

\section{THE VIRTUAL RECONSTRUCTION OF SLUICE BOX}

\subsection{The concept of the digital rearrangement}

The core concept of this work can be summarized as follows: The virtual rearrangement of the sluice box became feasible through the combination of the terrestrial- and short range laser scanning datasets. The three-dimensional model of the terrestrial laser scan data was the basis for the reconstruction process, because the original position of the find was documented with the terrestrial laser scanner at the archaeological site. For this reason, the single digital models of the close range laser scans were transformed in this original position by "Best Fit Alignment" in PolyWorks ${ }^{\circledR}$ Software. After this data alignment, the overall average difference between the terrestrial and close range laser scanning models was less than $4 \mathrm{~mm}$ (Figure 7). 


\subsection{The spatial comparison of the various construction elements}

The involved archaeologists investigate the Bronze Age orewashery techniques at the Mitterberg region and the first important research question could be answered by our project part after the virtual rearrangement of the sluice box parts. Is the crossbar above or below the holes levels of the wooden boards? Figure 6 shows the answer: One hole is located above the crossbar and the other hole lies at the level of the crossbar. At this time, the exact ore-washery process is in the reconstruction phase and the archaeologists try to simulate the water flow through the sluice box by crucial help of our achieved 3D results.

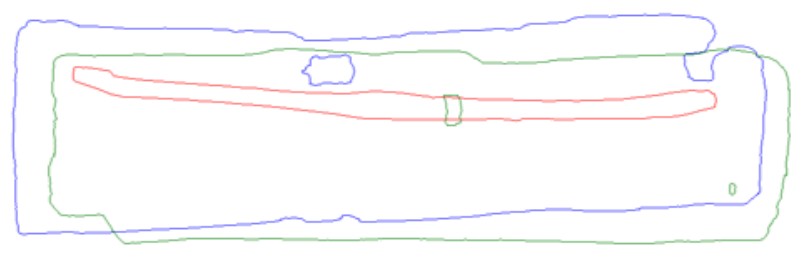

$10 \mathrm{~cm}$

Figure 6. The comparison of the crossbar and the wooden boards of the archaeological find

\section{ANALYSIS OF THE TOOL MARKS IN GIS ENVIRONMENT}

\subsection{The preparation of the object}

Numerous tool marks were even visually identified on the surface of the fully preserved sluice box at the archaeological site in the fall of 2009. The excavated parts of the unique find were accurately cleaned and stored in a mine entrance area, where the climatic conditions, such as humidity and temperature stayed constant. The smallest deformation of the object surface can generate error opportunities in the documentation process. For this reason, the survey with the FARO LaserScanArm was performed also in this room in early 2010. After the data collection, one wooden board of the box was selected by the archaeologists, where the tool marks were most significant. Finally, the investigation of these micro-relief structures was feasible in digital environment.

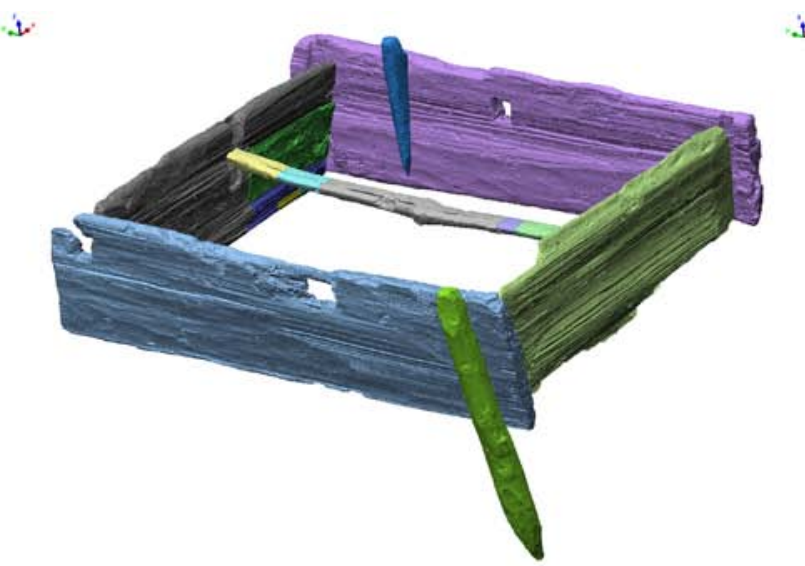

\subsection{The concept of the analysis}

Improvement of the remote sensing data acquisition and evaluation opens several research possibilities, especially the investigation of Earth's surface with aerial photographs and with satellite images so becoming very important for geomorphology studies during the last decades. The surface analysis of digital terrain models was continuously developed also in GIS environments and numerous investigation methods are possible using these software products. But these methods can be also used in some fields of archaeological science, such as the tool marks investigations of an archaeological object, because the characteristics of micro-relief structures of finds are similar to the characteristics of Earth's surface.

\subsection{Slope and aspect calculation}

In our case, a regular raster model was created based on the high-resolution point cloud of the excavated and scanned wooden board. This GIS data type consists of a matrix with every element storing a single value. The changes of the surface can be analyzed by the comparison of the different raster values. This raster analysis can be accomplished with any GIS software. At first, the XYZ axes of our model space were determined during the point cloud importation process in the ArcGIS ${ }^{\circledR}$. Therefore, the values of the raw datasets were ordered to this well-defined model space. After the surface interpolation, slope and aspect calculations were utilized to investigate the archaeological find. The maximum change in Z-direction of each raster cell can be assessed by the slope calculation and the aspect values can be determined by slope direction of the surface. In the following, these two results were blended with the hillshade model, because the visualisation of the tool marks was more effective with this blending technique (Figure 8).

Various unperceived patterns of the wooden board could be visualized by these methods. The regular pattern of the proposed tools movement was constituted from the directionand the depth analysis of the tool marks.

Figure 7. The virtual reconstruction of the archaeological find after the combination of different datasets (left) and the comparison of short-range- and terrestrial laser scanning datasets (right) 

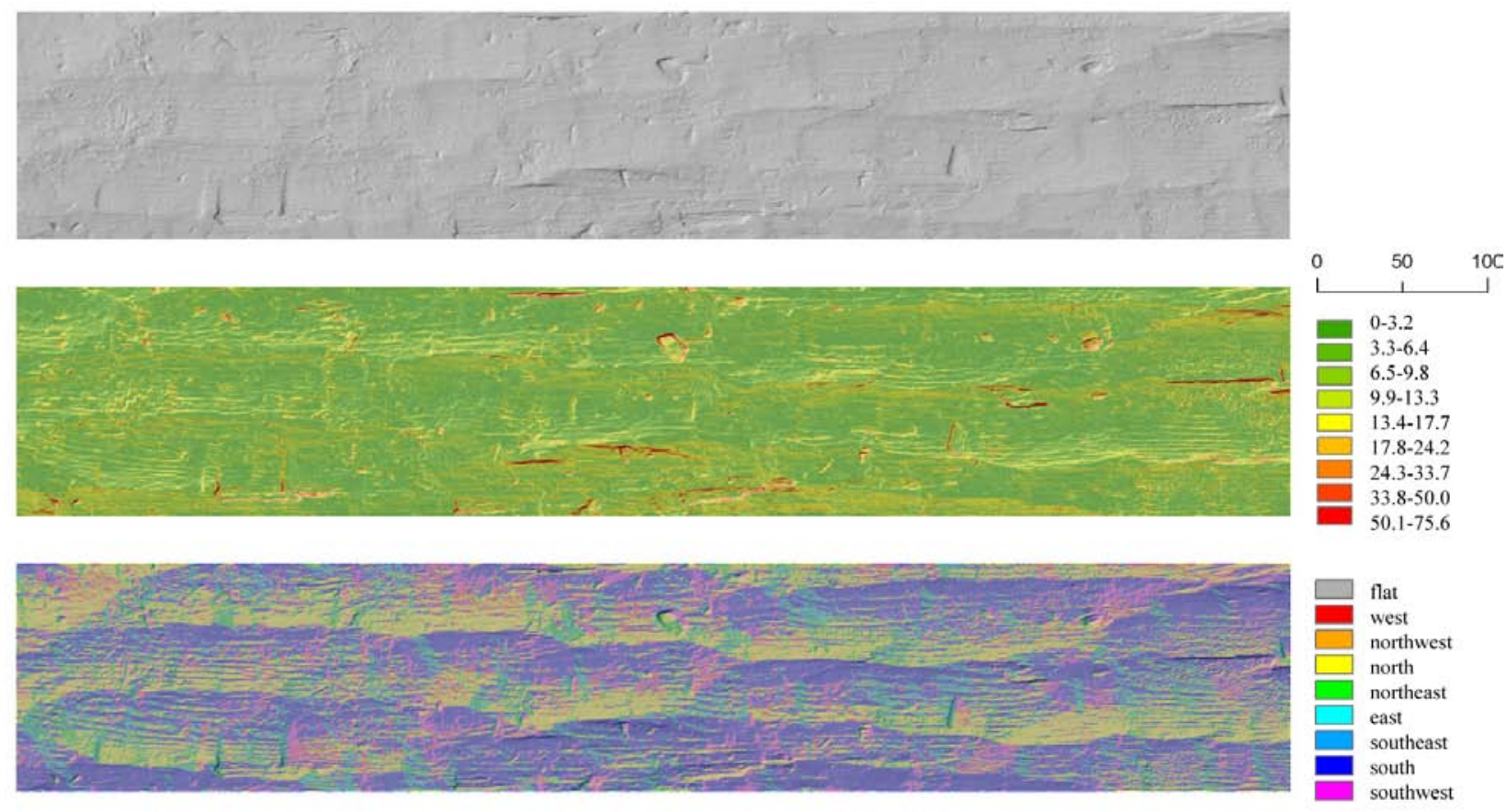

Figure 8. Surface analysis of the archaeological find in mm (up: hillshade model, middle: slope analysis, down: aspect analysis)

\section{CONCLUSION AND FUTURE WORK}

The sluice box from Mitterberg was accurately surveyed and documented. As a result, we obtained a high-resolution 3D digital model of this unique find after the virtual re-arrangement of the single parts. Farther researches were accomplished with these datasets, such as the investigation of the crossbar position in the centre of the sluice box. Finally, the spatial analysis of the tool marks was executed in GIS environment.

The overlaps of these fine surface structures implicate a complicated challenge at the accurate separation of the different tool movements. Further analysis techniques, for instance, raster processing in GIS, are scheduled to resolve these issues. The development of various digital investigation methods provides fundamental research opportunities during this assignment.

The significance of this project is on one hand to combine various methods in order to achieve more efficient documentation workflow, and on the other hand, to create more accurately archaeological 3D models and provide analysis tools that may have an important impact on the archaeological research of bronze-age mining and its methods and development in Central Europe.

\section{ACKNOWLEDGMENT}

The work is generously supported by the Austrian Science Fund (FWF Project F3114) in the framework of the Special Research Program "History of Mining Activities in the Tyrol and Adjacent Areas" (SFB HiMAT) as well as by the Austrian province governments of Tyrol, Vorarlberg and Salzburg, the Autonomous Province Bozen-South Tyrol, Italy, the local authorities of the mining areas concerned, the TransIDEE foundation and the University of Innsbruck, Austria.

\section{REFERENCES}

Hanke, K., Hiebel, G., Kovacs, K., Moser, M., 2010. Documentation Challenges in an International and Interdisciplinary Research Project. Proceedings of the ISPRS Commission V Midterm-Symposium in Newcastle upon Thyne, UK. In: The ISPRS International Archives of Photogrammetry, Remote Sensing and Spatial Information Sciences Volume 39(5)

Kovács, K., Moser, M., Hanke K., 2009. Application of laser scanning for archaeological prospection and 3D documentation. In: Museen der Stadt Wien - Stadtarchäologie (Hrsg.), Workshop 14 - Archäologie und Computer 2009. Phoibos, Wien. (E-Book) ISBN 978-3-200-02112-9

Moser, M., Hye, S., Goldenberg, G., Hanke, K., Kovacs, K., 2009. Digital documentation and visualization of archaeological excavations and finds using 3D scanning technology. In Proc. ARQUEOLOGICA 2.0 (1st International Meeting on Graphic Archaeology and Informatics, Cultural Heritage and Innovation). Sevilla, Spanien, 2009.

Petrie, G., Toth, C. K., 2009. 'Introduction to Laser Ranging, Profiling, and Scanning' in Shan, J. and Toth, C. K (ed.) Topographic laser ranging and Scanning - Principles and Processing Boca Raton: CRC Press

Stöllner, T., 2008. Bronzezeitliche Massenproduktion von Kupfer am Mitterberg. Archäologie in Deutschland vol. 4, pp. 32-33. 